\title{
Transcatheter devices for direct annuloplasty and chordal replacement in degenerative mitral regurgitation
}

\author{
J. James Edelman ${ }^{1}$, Christopher U. Meduri ${ }^{2}$, Gerald Yong ${ }^{3}$, Vinod H. Thourani ${ }^{4}$ \\ ${ }^{1}$ Department of Cardiothoracic Surgery, Fiona Stanley Hospital, Perth, Australia; ${ }^{2}$ Department of Cardiology, Marcus Valve Center, Piedmont Heart \\ Institute, Atlanta, GA, USA; ${ }^{3}$ Department of Cardiology, Fiona Stanley Hospital, Perth, Australia; ${ }^{4}$ Department of Cardiovascular Surgery, Marcus \\ Valve Center, Piedmont Heart Institute, Atlanta, GA, USA \\ Correspondence to: Vinod H. Thourani, MD. Department of Cardiovascular Surgery, Marcus Valve Center, Piedmont Heart Institute, 95 Collier Road, \\ Suite 5015, Atlanta, GA 30308, USA. Email: vinod.thourani@piedmont.org.
}

Submitted Jun 03, 2020. Accepted for publication Jul 03, 2020.

doi: 10.21037/acs-2020-mv-108

View this article at: http://dx.doi.org/10.21037/acs-2020-mv-108

\section{Introduction}

The two main principles of surgical mitral valve (MV) repair for primary mitral regurgitation (MR) are underpinned by restoration of the chordal support to the free edge of the leaflet, most often by leaflet resection or chordal replacement, and annuloplasty to reverse or prevent annular dilatation. The success and durability of this operation, when performed well, is best illustrated in the long-term follow-up series by David and Carpentier $(1,2)$. Within the last decade, transcatheter therapies have increasingly attempted to duplicate the superb surgical outcomes for primary MR. Most notably, the transseptal MitraClip (Abbott, Abbott Park, IL, USA) technology has replicated Alfieri's "edge-to-edge" repair and is used worldwide with more than 100,000 implants. In the U.S., MitraClip is available in patients with primary MV disease for those patients who are at too high-risk for traditional $\mathrm{MV}$ surgery. Although MitraClip is used commonly in Europe for secondary MR, it is anticipated that usage in the U.S. for this indication will occur soon with the positive results of the recently published COAPT trial (3). There are no commercially available options available for transcatheter $\mathrm{MV}$ replacement; however, several devices are in early feasibility study (EFS) or pivotal trials worldwide (4). Herein, we briefly review emerging transcatheter technologies with published trial data aiming to replicate chordal replacement and annuloplasty techniques of primary MR.

\section{Direct annuloplasty}

Transcatheter direct annuloplasty devices may be of use in high-risk patients with functional MR or in combination with other leaflet treatments for degenerative MR. Trials are also underway for direct annuloplasty devices for treatment of tricuspid valve regurgitation (TR). The Cardioband (Edwards, Irvine, CA, USA) is a percutaneously placed posterior annuloplasty device. Anchors are screwed into the posterior annulus and an annuloplasty band tightened in real-time under transesophageal echocardiography (TEE) guidance to reduce annular diameter. The 1-year outcomes of sixty patients with moderate or severe functional MR have been reported. Two deaths were reported during index hospitalization and $\leq$ mild MR was reported in $65 \%$ of patients (5). Several other devices are in EFS phase trials. The Millipede IRIS annuloplasty device is a semirigid complete nickel-titanium ring with eight anchors to attach to the entire mitral annulus, which are subsequently tensioned to achieve annular reduction. It is delivered transseptally, and uses an intra-cardiac echocardiogram (ICE) probe, passed through the central lumen to precisely guide annuloplasty placement. There are reported results for seven patients with $100 \%$ procedural success (6). The Valcare AMEND (Valcare Medical, Israel) device is another transcatheter complete ring which is currently transapical but is trialing a transseptal approach (NCT02602613).

\section{Chordal replacement}

Transcatheter chordal replacement is the closet mimic of traditional surgical repair for primary MR. Chordal replacement therapies are reserved for those with Carpentier 
type II degenerative disease; a predicted coaptation length of at least $3-5 \mathrm{~mm}$ is required. The majority of patients in the initial clinical experiences have had isolated posterior leaflet prolapse, but prolapse of the anterior leaflet is not a contraindication for some devices.

Two devices offer beating heart MV repair with chordal replacement from a transapical approach: the Harpoon (Edwards Lifesciences, Irvine CA, USA) and NeoChord (NeoChord, St. Louis Park, MN, USA). These devices allow MV repair using a minimally invasive transapical incision and do not require cardiopulmonary bypass. Both utilize a delivery system which deploys replacement chords under transesophageal guidance to the prolapsed leaflet, which are then secured just lateral to the apex and can be altered under TEE guidance on the beating heart to optimize length and minimize MR.

Over 1,000 patients have been treated with the NeoChord device in Europe, which received CE mark in 2013. In an EFS, only 17 of 30 patients achieved reduction of MR at 30 days (12 of the last 14 patients in the series) (7). A series of 213 patients (including P2, multi-segment posterior leaflet and complex anterior leaflet, commissural disease, and calcified leaflets) reported excellent 1-year survival (98\%) and $84 \%$ freedom from mortality, stroke, recurrence of severe MR, re-hospitalization or decrease in New York Heart Association (NYHA) functional class (8). The ReChord trial is currently randomizing patients to the NeoChord or surgery in those with severe MR from posterior leaflet prolapse (NCT02803957).

The Harpoon device has reported results from a multicenter, European EFS of 30 patients (9). They noted no mortality, but two patients required intra-operative conversion to surgery due to inadequate reduction of MR and another patient developed infective endocarditis prior to 30 days and underwent surgery. Twenty-six patients had echocardiographic follow-up at 6 months, 22 (85\%) had no more than mild MR, two patients had moderate MR and two had severe MR. One patient with severe MR underwent surgery. Critics of the transcatheter chordal replacement technique will argue that successful and durable repair of degenerative disease of the $M V$ requires placement of ring annuloplasty (or band) to restore the physiological size and shape of the MV annulus, and to prevent future dilatation; however, Gammie and Colleagues report a 31\% reduction in MV orifice area and $19 \%$ reduction in septal-lateral dimension with chordal replacement only (9). Restoration of coaptation and reduction of MR leading to promoting reverse remodeling together with the force from the antero- apically based neochords have been proposed as mechanisms for not requiring an annuloplasty devices in some selected patients. Long term follow-up will be required to assess the long-term durability of these novel approaches.

There are various transseptal approaches for chordal replacement therapy that are in development and are undergoing initial human experience including: Pipeline Medical by Gore Vascular (Flagstaff, AZ, USA) or ChordART (CoreMedic, Radolzell, Germany).

\section{Discussion}

Transcatheter techniques that mimic the current "gold standard" surgical MV repair are in an exciting developmental stage. There are reports of combining transcatheter chordal replacement and annuloplasty techniques, either in the same procedure or staged (10). The availability of larger series with longer followup are eagerly awaited and should prompt randomized comparisons to surgery. There is an increasing push to avoid transapical access. Inferior outcomes of transthoracic access in transcatheter aortic valve replacement (TAVR), together with improved technology allowing transfemoral or jugular vein access in the majority of patients have made transthoracic TAVR rare. Those technologies that adopt a transseptal approach will ultimately be more appealing to patients.

The excellent results and durability of surgical MV repair are challenging for transcatheter technologies to replicate. The long-term results regularly quoted from these series performed by expert surgeons, however, may not represent "real-world" data; large series of surgical MV repair with longer follow-up are needed to understand the true durability and success of mitral repair outside of these centers. We encourage randomized comparisons of new technologies to surgery. Even after these trials are complete, it is possible, however, that patients may be willing to accept inferior results and durability for the opportunity to avoid surgery, whether it be by sternotomy or a minimally invasive approach.

\section{Acknowledgments}

Funding: None.

\section{Footnote}

Conflicts of Interest: Dr. VHT: consultant and research: 
Abbott Vascular, Boston Scientific, Edwards Lifesciences, and Gore Vascular. The other authors have no conflicts of interest to declare.

Open Access Statement: This is an Open Access article distributed in accordance with the Creative Commons Attribution-NonCommercial-NoDerivs 4.0 International License (CC BY-NC-ND 4.0), which permits the noncommercial replication and distribution of the article with the strict proviso that no changes or edits are made and the original work is properly cited (including links to both the formal publication through the relevant DOI and the license). See: https://creativecommons.org/licenses/by-nc-nd/4.0/.

\section{References}

1. Braunberger E, Deloche A, Berrebi A, et al. Very longterm results (more than 20 years) of valve repair with carpentier's techniques in nonrheumatic mitral valve insufficiency. Circulation 2001;104:18-11.

2. David TE, Armstrong S, Ivanov J. Chordal replacement with polytetrafluoroethylene sutures for mitral valve repair: a 25-year experience. J Thorac Cardiovasc Surg 2013;145:1563-9.

3. Stone GW, Lindenfeld J, Abraham WT, et al. Transcatheter mitral-valve repair in patients with heart failure. N Engl J Med 2018;379:2307-18.

4. Testa L, Popolo Rubbio A, et al. Transcatheter mitral valve replacement in the transcatheter aortic valve

Cite this article as: Edelman JJ, Meduri CU, Yong G, Thourani VH. Transcatheter devices for direct annuloplasty and chordal replacement in degenerative mitral regurgitation. Ann Cardiothorac Surg 2021;10(1):164-166. doi: 10.21037/acs2020-mv-108 replacement era. J Am Heart Assoc 2019;8:e013352.

5. Messika-Zeitoun D, Nickenig G, Latib A, et al. Transcatheter mitral valve repair for functional mitral regurgitation using the Cardioband system: 1 year outcomes. Eur Heart J 2019;40:466-72.

6. Rogers JH, Boyd WD, Smith TW, et al. Early experience with Millipede IRIS transcatheter mitral annuloplasty. Ann Cardiothorac Surg 2018;7:780-6.

7. Seeburger J, Rinaldi M, Nielsen SL, et al. Off-pump transapical implantation of artificial neo-chordae to correct mitral regurgitation: the TACT Trial (Transapical Artificial Chordae Tendinae) proof of concept. J Am Coll Cardiol 2014;63:914-9.

8. Colli A, Manzan E, Aidietis A, et al. An early European experience with transapical off-pump mitral valve repair with NeoChord implantation. Eur J Cardiothorac Surg 2018;54:460-6.

9. Gammie JS, Bartus K, Gackowski A, et al. Beatingheart mitral valve repair using a novel ePTFE Cordal Implantation Device: a prospective trial. J Am Coll Cardiol 2018;71:25-36.

10. von Bardeleben RS, Colli A, Schulz E, et al. First in human transcatheter $\mathrm{COMBO}$ mitral valve repair with direct ring annuloplasty and neochord leaflet implantation to treat degenerative mitral regurgitation: feasibility of the simultaneous toolbox concept guided by $3 \mathrm{D}$ echo and computed tomography fusion imaging. Eur Heart J 2018;39:1314-5. 